\title{
Predators on private land: broad-scale socioeconomic interactions influence large predator management
}

\author{
Hayley S. Clements ${ }^{1}$, Graeme S. Cumming ${ }^{1,2}$ and Graham I. H. Kerley ${ }^{3}$
}

\begin{abstract}
The proliferation of private land conservation areas (PLCAs) is placing increasing pressure on conservation authorities to effectively regulate their ecological management. Many PLCAs depend on tourism for income, and charismatic large mammal species are considered important for attracting international visitors. Broad-scale socioeconomic factors therefore have the potential to drive fine-scale ecological management, creating a systemic scale mismatch that can reduce long-term sustainability in cases where economic and conservation objectives are not perfectly aligned. We assessed the socioeconomic drivers and outcomes of large predator management on 71 PLCAs in South Africa. Owners of PLCAs that are stocking free-roaming large predators identified revenue generation as influencing most or all of their management decisions, and rated profit generation as a more important objective than did the owners of PLCAs that did not stock large predators. Ecotourism revenue increased with increasing lion (Panthera leo) density, which created a potential economic incentive for stocking lion at high densities. Despite this potential mismatch between economic and ecological objectives, lion densities were sustainable relative to available prey. Regional-scale policy guidelines for free-roaming lion management were ecologically sound. By contrast, policy guidelines underestimated the area required to sustain cheetah (Acinonyx jubatus), which occurred at unsustainable densities relative to available prey. Evidence of predator overstocking included predator diet supplementation and frequent reintroduction of game. We conclude that effective facilitation of conservation on private land requires consideration of the strong and not necessarily beneficial multiscale socioeconomic factors that influence private land management.
\end{abstract}

Key Words: cheetah Acinonyx jubatus; cross-scale interaction; ecotourism; financial objectives; lion Panthera leo; minimum area requirements; predator management; social-ecological

\section{INTRODUCTION}

Many of the challenges encountered by societies in managing natural resources arise because of a mismatch between the scale of management and the scale of ecological processes being managed (Cumming et al. 2006). For example, in the absence of regional and global institutions with the power to regulate fishing harvests at spatial and temporal scales that are appropriate for (often poorly understood) fish population dynamics, societies have overexploited fish populations (Hilborn et al. 2005). Mitigating such challenges requires an understanding of the multiscale processes that influence management and the development of approaches for realigning socioeconomic and ecological system elements.

Private landowners have become important role players in conserving and connecting biodiversity globally (Fitzsimons and Wescott 2008, Gallo et al. 2009, Stolton et al. 2014). Private land conservation areas (PLCAs) are managed for biodiversity conservation objectives, with possible secondary objectives, including nature tourism and game-based ventures (Stolton et al. 2014). Despite the importance of PLCAs for biodiversity conservation, there are concerns that unsustainable ecological management on some PLCAs will undermine their long-term conservation objectives. Firstly, PLCAs often comprise relatively small tracts of land $(<10,000 \mathrm{ha})$; there are concerns that many PLCAs are too small to effectively conserve species with large spatial requirements, such as megaherbivores and large predators (Creel et al. 2013, Miller and Funston 2014). Secondly, the financial objectives of many PLCAs and their reliance on incomegenerating activities may result in ecological management decisions that are heavily influenced by the expectations of paying visitors (Langholz and Lassoie 2001, Cousins et al. 2010, Miller et al. 2013, Maciejewski and Kerley 2014a). The perception that visitors demand high quality sightings of charismatic megaherbivores and large predators may lead to unsustainable stocking rates of large mammals (Lindsey et al. 2007, Kettles and Slotow 2009, Maciejewski and Kerley 2014b). Conservation authorities have the ability to mitigate these concerns by way of policy. For example, in order to introduce "dangerous game" (megaherbivores and large predators) onto a PLCA in South Africa, the owner is required to obtain a Certificate of Adequate Enclosure by fulfilling requirements outlined in the relevant provincial (i.e., regional) policy (e.g., Department of Economic Development and Environmental Affairs 2008).

The potential interactions between owner objectives, land size, policy, tourist demands, and large mammal management are multiscale. A manager with a given land area may reintroduce charismatic large mammal species (ecological elements at the PLCA scale) as a result of the owner's financial objectives (socioeconomic elements at the PLCA scale) and the perceived demand from tourists (socioeconomic elements at the national and international scale) (Fig. 1) (Maciejewski et al. 2015). Stocked mammals thereafter impact on other patch- and PLCA-scale ecological elements, through habitat and/or prey preferences (Fig. 1 ), resulting in potentially deleterious ecological effects if these species are overstocked relative to resource requirements (Kerley and Landman 2006, Kettles and Slotow 2009). Regional-scale policy may prevent PLCA-scale overstocking, provided policy requirements are ecologically meaningful, and enforced (Fig. 1).

${ }^{1}$ Percy FitzPatrick Institute, DST/NRF Centre of Excellence, University of Cape Town, South Africa, ${ }^{2}$ ARC Centre of Excellence for Coral Reef Studies, James Cook University, Australia, ${ }^{3}$ Centre for African Conservation Ecology, Nelson Mandela Metropolitan University, South Africa 
Fig. 1. Summary of multiscale socioecological patterns and processes related to large charismatic mammal management on private land conservation areas (PLCAs), based on the protected area framework presented in Cumming et al. (2015) and Maciejewski et al. (2015). Each unit represents both a spatial scale (akin to traditional ecological spatial scales [Poiani et al. 2000]) and an institutional level.

\begin{tabular}{|c|c|c|}
\hline Ecological units & Scale & Institutional/social units \\
\hline $\begin{array}{c}\text { Network of PLCAs between } \\
\text { which large mammals are } \\
\text { translocated } \\
\text { International institutional } \\
\text { context }\end{array}$ & $\begin{array}{c}\text { National } \\
\text { National institutional } \\
\text { context }\end{array}$ & International tourists \\
\hline $\begin{array}{c}\text { Network of PLCAs between } \\
\text { which large mammals are } \\
\text { translocated }\end{array}$ & $\begin{array}{c}\text { Regional/provincial } \\
\text { Proximate institutional } \\
\text { context }\end{array}$ & $\begin{array}{c}\text { Provincial government policies } \\
\text { regarding stocking large } \\
\text { mammals }\end{array}$ \\
\hline $\begin{array}{c}\text { Large mammal stocking densities } \\
\text { within a fenced area }\end{array}$ & $\begin{array}{c}\text { PLCA } \\
\text { Single tenure unit }\end{array}$ & $\begin{array}{c}\text { PLCA owner and manager } \\
\text { objectives, PLCA revenue derived } \\
\text { from ecotourism }\end{array}$ \\
\hline $\begin{array}{c}\text { Large mammal habitat and/or prey } \\
\text { preferences; habitat and prey } \\
\text { composition and distribution }\end{array}$ & $\begin{array}{c}\text { Patch } \\
\text { sub- } \\
\text { tenure } \\
\text { unit }\end{array}$ & $\begin{array}{c}\text { PLCA management actions } \\
\text { regarding large mammals (e.g., } \\
\text { water provision, population control) }\end{array}$ \\
\hline
\end{tabular}

To explore the relevance of multiscale socioeconomic factors for the management of PLCAs, we focused on PLCAs that stock large predators (cheetah [Acinonyx jubatus], lion [Panthera leo], spotted hyaena [Crocuta crocuta], wild dog [Lycaon pictus)]) in the Eastern and Western Cape Provinces of South Africa. Applying the concept of scale mismatches, we predicted that unsustainable stocking densities of large predators might arise if (1) policy guidelines related to predator management were inappropriate, and/or (2) PLCA owners expressed financial objectives, and ecotourism revenue was higher at higher densities of large predators.

\section{METHODS}

\section{Study region}

With $79 \%$ of South Africa's land area in private hands (Department of Rural Development and Land Reform 2013), and with the devolution of wildlife user rights to the landowner incentivizing game-based ventures, private land has become an important part of the national conservation effort (Bond et al. 2004). PLCAs in South Africa include "Private Nature Reserves" that are legally gazetted under the Protected Areas Act (Act 57 of 2003, as amended), "Biodiversity Agreements" that have legal status by virtue of a legally binding contract, and "Conservation Areas" that are not legally recognized but receive some form of protection by the landowners and are managed at least partly for biodiversity conservation (Cadman 2010). PLCAs in South Africa vary widely in their management objectives and approaches (Langholz 1996, Pasquini et al. 2010, Child et al. 2013, Stolton et al. 2014, Selinske et al. 2015).

\section{Sample selection}

A list of PLCAs in the Eastern and Western Cape Provinces of South Africa was compiled using the South African Protected Areas Database (Department of Environmental Affairs 2016). This list was augmented by online searches using keywords such as private, game, nature, and reserve. Commercially operated PLCAs were selected using a stratified random approach to meet the PLCA definition while providing diversity in size, geographical location, ecology, legal status, facilities, and activities. Meetings with managers or managing owners of 71 PLCAs took place between April 2014 and February 2015.

Determining predator presence and observed predator densities The South African cadastral farm boundary data (AfriGIS 2013) were used to determine the area of each PLCA. Managers were asked to state which (if any) large predator species (cheetah, lion, spotted hyaena, wild dog) had been reintroduced onto the PLCA. Leopard (Panthera pardus) were excluded from this list because they are not constrained by fences, have vast home ranges that span multiple properties, and their secretive nature means that they are rarely seen by tourists (Hayward et al. 2007a, Fattebert et al. 2015). Spotted hyaena occurred on one PLCA, and wild dog did not occur on any PLCAs (see Results); therefore, they were excluded from further analyses. Managers were asked whether predators had access to the entire PLCA or were maintained within a subsection of the PLCA. Free-roaming lion and cheetah were defined as those occurring on a minimum area of 2000 ha or 1000 ha, respectively (see Comparing sustainable predator densities with policy guidelines). Predators that occurred in areas less than this are hereafter referred to as "captive" predators. The population size and density of each free-roaming, large predator species that occurred on each PLCA in 2013 was recorded. If the predator(s) occurred on a subsection of a PLCA, the area of this section was used to determine density. These predator densities are hereafter referred to as "observed predator densities."

\section{Assessing the influence of owners' financial objectives on predator management}

Managers were asked to rate profit generation as an owner's objective for the PLCA, using a Likert scale from one (not important) to five (very important). If managers stated that they were unable to answer this question, the owner was contacted. Ratings from PLCAs that stocked free-roaming predators ("predator-present PLCAs") were compared to those from PLCAs that did not stock predators (neither free-roaming nor captive; "predator-absent PLCAs"), using a Wilcoxon signedrank test (R package: stats; function: wilcox.test [R Development Core Team 2013]). Managers of PLCAs that stocked freeroaming predators were further asked to state how often PLCA revenue informed their decisions regarding PLCA management, and answers were allocated a frequency category: never, occasionally, mostly, or always.

\section{Assessing the influence of predator management on ecotourism} revenue

Total ecotourism revenue generated during the 2013/2014 financial year was obtained for 11 predator-present PLCAs and 37 predator-absent PLCAs. Ecotourism revenue included payments for entrance, food, accommodation, and activities. Activities included game- and nature-viewing drives and walks, game interaction opportunities, horse riding, quad biking and 
off-road driving, events and functions, and environmental programs. Ecotourism revenue was recorded in South African Rand and converted to United States Dollar using the average South African Reserve Bank daily exchange rate for the 2013/2014 financial year ( $1 \mathrm{USD}=10.00 \mathrm{ZAR})$. Ecotourism revenue was compared between predator-present and predator-absent PLCAs using a Wilcoxon signed-rank test.

On predator-present PLCAs for which both predator density and ecotourism revenue were available $(n=10)$, we used linear models to assess whether (a) observed lion density, and (b) observed cheetah density were significant predictors of ecotourism revenue ( $\mathrm{R}$ package: stats; function: $1 \mathrm{~m}$ [R Development Core Team 2013]). Plots of fitted and observed values and residuals were examined for deviations from the assumptions of homogeneity and normality. Ecotourism revenue was square root transformed in order to meet these assumptions. The adjusted coefficient of determination was used to assess model fit.

\section{Determining sustainable predator densities}

Ungulate count data from 2013 or the most recent year prior to 2013 were obtained from predator-present PLCAs. Ungulates that are difficult to count due to their habitat preferences, solitary nature, and/or small size (common duiker [Silvicapra grimmia], grysbok [Raphicerus melanotis], klipspringer [Oreotragus oreotragus], steenbok [Raphicerus campestris)]), and thereby absent in many PLCAs' count data, were excluded. If predators occurred on a subsection of a PLCA, ungulate count data for that subsection were obtained.

The biomass $\left(\mathrm{kg} / \mathrm{km}^{2}\right)$ of the lion's preferred prey species has been shown to be a significant predictor of lion density, and the biomass $\left(\mathrm{kg} / \mathrm{km}^{2}\right)$ of prey in the cheetah's preferred prey weight range has been shown to be a significant predictor of cheetah density (Hayward et al. 2007b). These relationships can be used to determine the density of predators that a given prey population can sustain (Hayward et al. 2007b). This density is hereafter referred to as the "sustainable predator density." We used PLCA ungulate count data to determine the biomass $\left(\mathrm{kg} / \mathrm{km}^{2}\right)$ of preferred prey species of lion and the biomass $\left(\mathrm{kg} / \mathrm{km}^{2}\right)$ of prey species in the preferred weight range of cheetah on each PLCA that stocked these predators (Hayward et al. 2007b). Threequarters of the adult female body mass was used (to account for differences in mass between male, female, and juvenile prey individuals) (Skinner and Chimimba 2005, Hayward et al. 2007b). Ungulate count data were not corrected for visibility, as predator prey preferences and density equations were developed using uncorrected data (Hayward et al. 2007b), and correcting data would result in overestimations of sustainable predator densities.

Comparing sustainable predator densities with policy guidelines In the Eastern Cape Province, the Certificate of Adequate Enclosure and Dangerous Game Fencing Specifications Policy (Department of Economic Development and Environmental Affairs 2008) states that, together with compiling a management plan and meeting fencing specifications, "the recommended minimum area to introduce dangerous game is 2000 ha depending on topography, habitat, prey availability, and carrying capacity. (Hippopotamus and Cheetah are excluded from the minimum of 2000 ha and require 1000 ha depending on habitat and topography)." The Policy on Fencing and Enclosure of Game, Predators and Dangerous Animals in the Western Cape Province (Cape Nature Biodiversity Support Services 2014) provides no guidelines for minimum area requirements of "free-roaming" predators, but states that the required management plan should include "the maximum capacity per species provided for at the facility." For PLCAs that stocked lion, we used estimated sustainable lion densities to determine the number of lion that could be sustainably supported on the specified minimum required area of 2000 ha. Similarly, the number of cheetah that could be sustainably supported on the specified minimum required area of 1000 ha was determined for each PLCA that stocked cheetah.

\section{Assessing the sustainability of predator management}

We assessed whether PLCAs were over- or under-stocking their PLCAs relative to sustainable predator densities. For each predator-present PLCA, we compared the observed density of each predator species with the sustainable density, using a paired sample $t$ test where data met the assumption of normality, and a paired Wilcoxon signed-rank test where data did not (R package: stats; functions: t.test and wilcox.test [R Development Core Team 2013]). Stocking densities at individual PLCAs were considered unsustainable if they exceeded sustainable density estimates by more than 5\%. Managers were asked whether they used predator contraception, sold/relocated predators, and/or supplemented predator diet on a regular basis, as well as whether they introduced additional game at least once every five years. We determined the proportion of managers who undertook these actions on PLCAs where all predator species were sustainably stocked, and those where at least one species was unsustainably stocked.

\section{RESULTS}

Of the 71 PLCAs sampled, 22 stocked at least one large predator species (Fig. 2). On average, these 22 PLCAs stocked two (1.8 \pm 0.1 ) large predator species, with a maximum of three species. Ten PLCAs supported all predators in "captivity" (i.e., within an area $<2000$ ha, or $<1000$ ha for cheetah), and 12 PLCAs supported "free-roaming" predators (i.e., within an area $>2000$ ha, or $>1000$ ha for cheetah). Free-roaming predators occurred on land areas ranging from 2300 ha to 54,400 ha (mean $=14,600$ \pm 4000 ha).

Fig. 2. Map of the Western and Eastern Cape Provinces of South Africa displaying the 22 surveyed private land conservation areas that stocked large predators, with 12 supporting free-roaming ("free") large predators, and 10 supporting captive large predators.

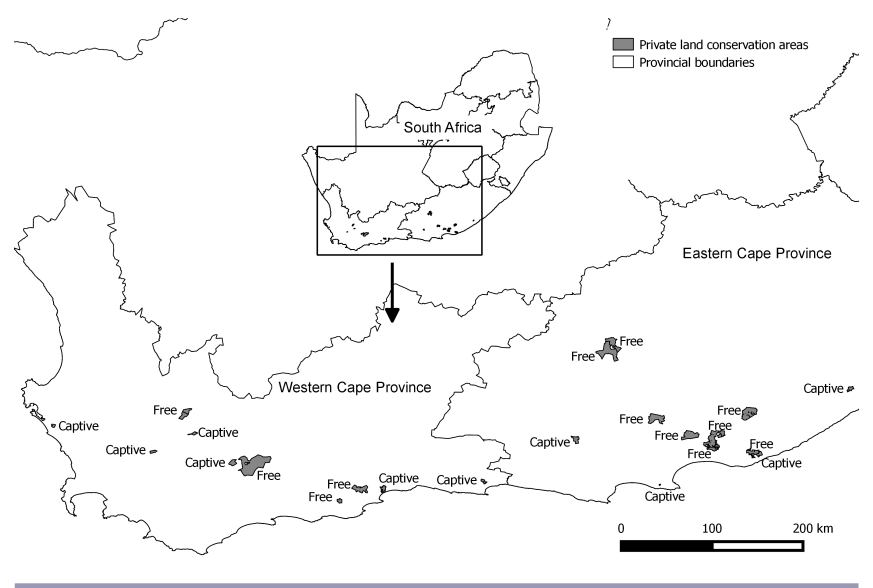


Free-roaming cheetah and lion co-occurred on five PLCAs (Appendix 1). Cheetah occurred as the sole predator on four PLCAs (Appendix 1). Lion co-occurred with spotted hyaena on one PLCA and as the sole predator on two PLCAs (Appendix 1). Average population sizes were $5 \pm 1$ cheetah and $8 \pm 2$ lion; average densities were $0.05 \pm 0.02$ cheetah $/ \mathrm{km}^{2}$ and $0.05 \pm 0.01 \mathrm{lion} / \mathrm{km}^{2}$ (Appendix 1). Wild dog were not present on any PLCAs.

The owners of all predator-present PLCAs rated profit generation to be an important objective (Likert rating $>3$ ), with $75 \%$ rating it as very important (Likert rating $=5$ ). Profit generation was rated as a significantly more important objective by the owners of predator-present PLCAs, compared with predator-absent PLCAs $\left(\right.$ mean $_{\text {present }}=4.8 \pm 0.1$, mean $_{\text {absent }}=3.7 \pm 0.2 ; \mathrm{W}=397.5$, $n_{1}=12, n_{2}=47, p=0.02$ ). PLCA revenue was used to inform all management decisions on $33 \%$ of predator-present PLCAs, and most management decisions on a further $50 \%$ of these PLCAs.

Predator-present PLCAs generated greater ecotourism revenues $($ mean $=\$ 2,224,495 \pm 655,650)$ than did predator-absent PLCAs (mean $\left.=\$ 170,500 \pm 85,678 ; W=355, n_{1}=10, n_{2}=37, p<0.001\right)$. On predator-present PLCAs, lion density explained $49.3 \%$ of the variation in ecotourism revenue $\left(F=9.77, \mathrm{df}_{1}=1, \mathrm{df}_{2}=8, p=\right.$ 0.01 ), with ecotourism revenue (square root transformed) increasing with increasing lion density $(\beta=12954 \pm 4145, t=3.39$, $p=0.01$ ) (Fig. 3a). Cheetah density was not a significant predictor of ecotourism revenue $\left(F=1.09, \mathrm{df}_{1}=1, \mathrm{df}_{2}=8, p=0.33\right)$ (Fig. $3 \mathrm{~b}$ ).

Fig. 3. The relationship between ecotourism revenue and (a) lion density, and (b) cheetah density on 10 private land conservation areas that stocked free-roaming large predators (five sites stocked both cheetah and lion, three sites supported cheetah only, and two sites supported lion only).
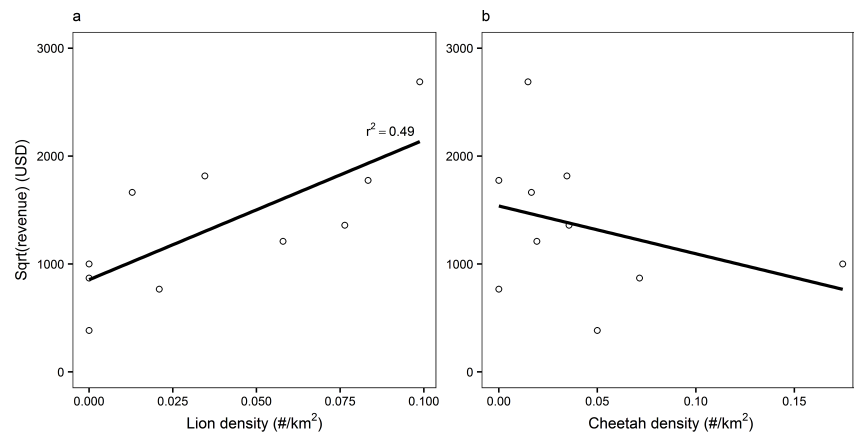

No PLCA that stocked free-roaming cheetah supported a sufficient biomass of preferred prey to sustain a single cheetah in the minimum area required by policy for the reintroduction of this species (i.e., 1000 ha) (Fig. 4). Most PLCAs that stocked freeroaming lion ( 7 out of 8 ) had sufficient preferred prey biomasses to sustain at least one lion in the minimum area required by policy (i.e., 2000 ha), and were capable of supporting $1.7 \pm 0.2$ lion per 2000 ha on average (Fig. 4).

On PLCAs that stocked free-roaming cheetah, observed cheetah stocking rates were significantly above the sustainability threshold ( $W=3, n=8, p=0.04$ ) (Fig. 5), with just two out of eight of these PLCAs supporting a sustainable density of cheetah. On
PLCAs that stocked free-roaming lion, observed lion stocking rates were significantly below the sustainability threshold $(t=$ 3.52, $\mathrm{df}=7, p=0.01$ ) (Fig. 5), with all PLCAs supporting a sustainable density of lion. Predator contraception took place on $80 \%$ and $83 \%$ of sustainably and unsustainably stocked PLCAs, respectively. Predator sales/relocations took place on all predatorpresent PLCAs. Predator diet was not supplemented on any PLCAs that supported sustainable predator densities, while predator diet was supplemented on $67 \%$ of PLCAs that supported unsustainable predator densities. Similarly, game were introduced at least once every five years on just $20 \%$, compared with $83 \%$, of PLCAs that supported sustainable versus unsustainable predator densities, respectively.

Fig. 4. Summary statistics across private land conservation areas that stocked free-roaming cheetah and lion, of the number of each large predator that can be sustainably supported in the minimum area required to obtain a Certificate of Adequate Enclosure for that predator [cheetah: 1000 ha; lion: 2000 ha) (Department of Economic Development and Environmental Affairs 2008). Lines, boxes, error bars, and circles show medians, interquartile ranges, minima, and maxima (excluding outliers), and outliers (that deviate from the median by $>$ $1 \mathrm{x}$ the interquartile range), respectively. Sustainable numbers were determined according to the available biomass $\left(\mathrm{kg} / \mathrm{km}^{2}\right)$ of preferred prey. The red dashed line indicates the threshold above which more than one individual can be sustained in the minimum required area.

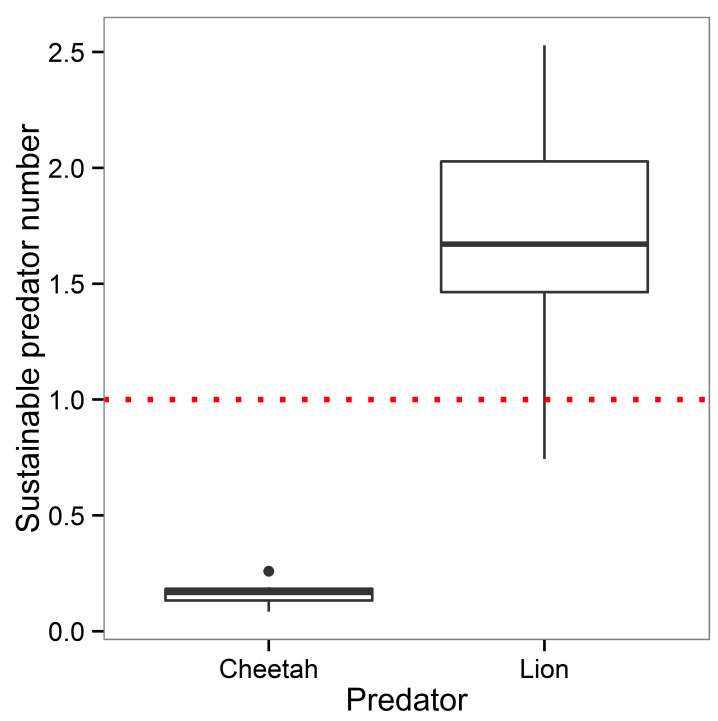

\section{DISCUSSION}

With greater ecotourism revenues generated on PLCAs where free-roaming large predators are present, there are clear financial incentives to stocking large predators. The owners of land that is supporting free-roaming large predators stated that revenue influenced most or all of their management decisions, and they rated profit generation to be a more important objective than did 
Fig. 5. Summary statistics across private land conservation areas (PLCAs) that stocked free-roaming cheetah and lion, of the difference between the observed predator density on a PLCA and the density of predators that can be sustainably supported on that PLCA. Lines, boxes, error bars, and circles show medians, interquartile ranges, minima, and maxima (excluding outliers), and outliers (that deviate from the median by $>1 \mathrm{x}$ the interquartile range), respectively. The dashed red line indicates the threshold above which observed predator density is unsustainable.

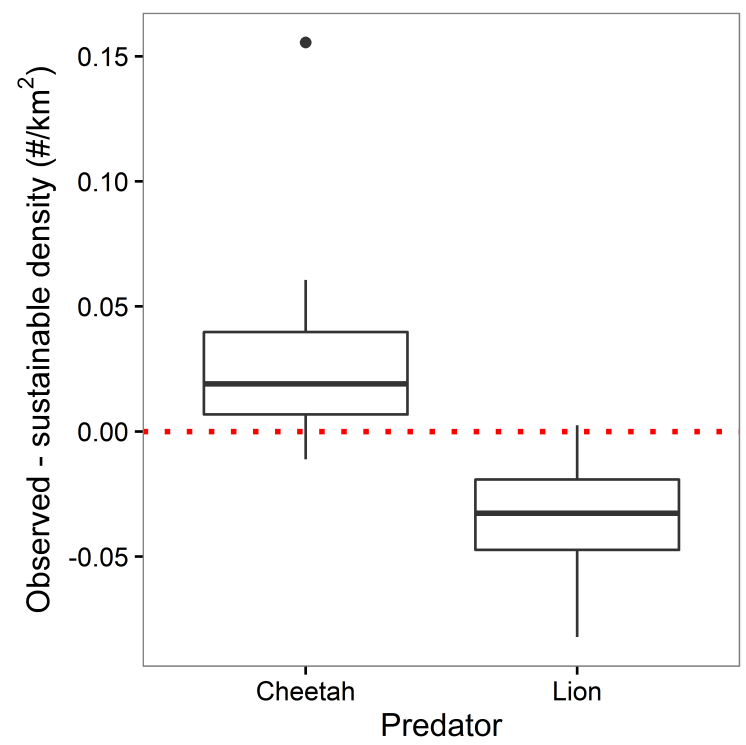

the owners of land that did not support large predators. Financial incentives extend beyond the stocking of large predators to the population management of specific species. There are incentives to stock lion at high densities, with a positive relationship evident between lion density and revenue generated from ecotourism. In contrast, cheetah density had no effect on ecotourism revenue. These differences are supported by previous research on tourist preferences; lion rank as a more desirable species to see than cheetah (Di Minin et al. 2013, Maciejewski and Kerley 2014a). Lion are a member of the "Big Five," a term coined by hunters as the five most difficult animals to hunt on foot, but latterly an important catchphrase adopted by the safari industry to market Africa's "most charismatic" species (Di Minin et al. 2013). We have not assessed the mechanism behind this observed relationship between lion density and revenue, and it is therefore important to note that (a) lion density may correspond with other important visitor pull factors, and (b) with a greater sample size we may be able to detect a threshold above which increased lion density no longer improves visitor sighting success rates and thereby revenues, as seen with elephants (Maciejewski and Kerley 2014b).

Despite the financial incentives to stock lion at high densities, observed lion densities were sustainable in relation to available prey biomass. Due to their high reproductive potential, lion and cheetah numbers can increase rapidly when the animals are introduced onto small, fenced reserves with abundant and naïve prey, thereby necessitating intensive management, such as relocation, contraception, and/or culling (Hunter 1998, Tambling and du Toit 2005, Miller and Funston 2014). Frequent contraception and relocation actions were reported as predator management tools by PLCA managers. While these actions appeared effective in maintaining lion at sustainable densities, they were ineffective for cheetah population management. Cheetah occurred above densities that could be sustained on the biomass of preferred prey available on most PLCAs.

The overstocking of large predators can have substantial ramifications for ecosystem functioning. In fenced PLCAs, such as those in this study, ungulates are unable to escape predation, and the consequence of predator population growth can be ungulate population declines and even collapses (Hunter 1998, Power 2003). PLCA managers can attempt to mitigate these impacts by frequently introducing additional prey or by supplementing their predators' diets with meat acquired elsewhere (Lindsey et al. 2011, Miller et al. 2013). Both of these actions were more prevalent on PLCAs that supported unsustainable, as opposed to sustainable, predator populations. Elevated predator densities may, however, still have a significant negative impact on certain prey species, particularly smaller preferred prey species that are impractical to reintroduce and monitor, and secondary prey species that are usually protected from predation through their scarcity relative to predator densities (Hayward 2011).

Effective management of free-roaming large predators requires knowledge regarding what predator densities are sustainable. The minimum area policy guideline of 2000 ha for lion is helpful in this regard. Sufficient prey biomasses were available to sustain at least one lion per 2000 ha on most PLCAs, which supports previous minimum area requirement estimates for lion (Creel and Creel 1997, Power 2003). In contrast, not a single PLCA supported sufficient prey to sustain a single cheetah per 1000 ha, which questions the soundness of this policy guideline (Department of Economic Development and Environmental Affairs 2008).

\section{GROUNDED SPECULATION}

While financial incentives arising from international- and national-scale tourist preferences influenced the introduction of large predators onto PLCAs, they appear less influential in guiding the subsequent management of these predator populations. A potential mismatch exists between financially desirable and ecologically sustainable lion densities, yet in actuality this mismatch did not appear to drive predator management, contrary to our prediction. With ecologically sound policy guidelines regarding lion area requirements corresponding with sustainable lion densities, it appears that policy can be a useful tool in promoting sustainable predator management. In contrast, mismatches between cheetah area requirements recommended by policy at a regional scale, and those which are appropriate at a PLCA scale, corresponded with evidence of unsustainable cheetah management, as predicted, with inappropriate policy therefore detrimental to predator conservation.

The predator-prey abundance models used to determine sustainable predator densities were developed in ecosystems that 
generally supported an intact large predator guild (Hayward et al. 2007b). In the absence of interguild competition for food, the application of these models to single-predator systems may result in an underestimation of sustainable predator densities. While we cannot exclude this potential bias, given that no alternative models exist, we show that management actions indicative of predator overstocking (feeding of predators and restocking of prey) are well aligned with our predictions of which predator populations are overstocked, which suggests our predictions are ecologically sound. It would be useful to further verify these predictions through evidence of declines in prey populations. Unfortunately, such data were unavailable for the study sites.

\section{CONCLUSION}

Global ecosystem changes are associated with substantial declines in apex predator numbers (Estes et al. 2011), making effective large predator conservation efforts imperative. Debate regarding the conservation value of small, fenced, privately owned, and intensively managed areas for large predator conservation continues (Creel et al. 2013, Packer et al. 2013). For conservation authorities to develop effective solutions that facilitate sustainable predator management on private land, they must consider the strong and not necessarily beneficial multiscale socioeconomic factors, such as international tourist preferences and regional policy recommendations, which influence private land management.

Responses to this article can be read online at: http://www.ecologyandsociety.org/issues/responses. $\mathrm{php} / 8607$

\section{Acknowledgments:}

We thank participating managers for their time and hospitality, and Timm Hoffman and three anonymous reviewers for valuable comments on an earlier version of this manuscript. This research was funded by a James S. McDonnell Foundation Complexity Scholar grant to GC and a GreenMatter Harry Crossley Fellowship and National Research Foundation (NRF-DAAD) scholarship to $H C$, with additional support from the DST-NRF Centre of Excellence at the Percy FitzPatrick Institute.

\section{LITERATURE CITED}

\section{AfriGIS. 2013. AfriGIS Cadastre.}

Bond, I., B. Child, D. de la Harpe, B. Jones, J. Barnes, and H. Anderson. 2004. Private land contribution to conservation in South Africa. Pages 29-62 in B. Child, editor. Parks in transition: biodiversity, rural development, and the bottom line. Earthscan, New York, USA.

Cadman, M. 2010. Biodiversity for development: South Africa's landscape approach to conserving biodiversity and promoting ecosystem resilience. South African National Biodiversity Institute, Pretoria, South Africa.

Cape Nature Biodiversity Support Services. 2014. Policy on fencing and enclosure of game, predators and dangerous animals in the Western Cape Province. Stellenbosch, South Africa.
Child, M. F., M. J. S. Peel, I. P. J. Smit, and W. J. Sutherland. 2013. Quantifying the effects of diverse private protected area management systems on ecosystem properties in a savannah biome, South Africa. Oryx 47(1):29-40. http://dx.doi. org/10.1017/s0030605312000038

Cousins, J. A., J. P. Sadler, and J. Evans. 2010. The challenge of regulating private wildlife ranches for conservation in South Africa. Ecology and Society 15(2):23. http://www.ecologyandsociety. org/vol15/iss2/art28/

Creel, S., M. S. Becker, S. M. Durant, J. M'Soka, W. Matandiko, A. J. Dickman, D. Christianson, E. Dröge, T. Mweetwa, N. Pettorelli, E. Rosenblatt, P. Schuette, R. Woodroffe, S. Bashir, R. C. Beudels-Jamar, S. Blake, M. Borner, C. Breitenmoser, F. Broekhuis, G. Cozzi, T. R. B. Davenport, J. Deutsch, L. Dollar, S. Dolrenry, I. Douglas-Hamilton, E. Fitzherbert, C. Foley, L. Hazzah, P. Henschel, R. Hilborn, J. G. C. Hopcraft, D. Ikanda, A. Jacobson, B. Joubert, D. Joubert, M. S. Kelly, L. Lichtenfeld, G. M. Mace, J. Milanzi, N. Mitchell, M. Msuha, R. Muir, J. Nyahongo, S. Pimm, G. Purchase, C. Schenck, C. Sillero-Zubiri, A. R. E. Sinclair, A. N. Songorwa, M. Stanley-Price, C. A. Tehou, C. Trout, J. Wall, G. Wittemyer, and A. Zimmermann. 2013. Conserving large populations of lions - the argument for fences has holes. Ecology Letters 16(11):1413-e3. http://dx.doi. org/10.1111/ele.12145

Creel, S., and N. M. Creel. 1997. Lion density and population structure in the Selous Game Reserve: evaluation of hunting quotas and offtake. African Journal of Ecology 35(2):83-93. http:// dx.doi.org/10.1111/j.1365-2028.1997.062-89062.x

Cumming, G. S., C. R. Allen, N. C. Ban, D. Biggs, H. C. Biggs, D. H. Cumming, A. De Vos, G. Epstein, M. Etienne, K. Maciejewski, R. Mathevet, C. Moore, M. Nenadovic, and M. Schoon. 2015. Understanding protected area resilience: a multiscale, social-ecological approach. Ecological Applications 25 (2):299-319. http://dx.doi.org/10.1890/13-2113.1

Cumming, G. S., D. H. M. Cumming, and C. L. Redman. 2006. Scale mismatches in social-ecological systems: causes, consequences, and solutions. Ecology and Society 11(1):14. http:// www.ecologyandsociety.org/vol11/iss 1/art14/

Department of Economic Development and Environmental Affairs. 2008. Operational Guidelines of the Chief Directorate of Environmental Affairs 2008: Certificate of Adequate Enclosure \& Dangerous Game Fencing Specifications. Bhisho, South Africa.

Department of Environmental Affairs. 2016. South African Protected Areas Database. Republic of South Africa.

Department of Rural Development and Land Reform. 2013. Land audit as approved by Cabinet, September 5, 2013. Pretoria, South Africa.

Di Minin, E., I. Fraser, R. Slotow, and D. C. MacMillan. 2013. Understanding heterogeneous preference of tourists for big game species: implications for conservation and management. Animal Conservation 16(3):249-258. http://dx.doi.org/10.1111/ j.1469-1795.2012.00595.X

Estes, J. A., J. Terborgh, J. S. Brashares, M. E. Power, J. Berger, W. J. Bond, S. R. Carpenter, T. E. Essington, R. D. Holt, J. B. C. Jackson, R. J. Marquis, L. Oksanen, T. Oksanen, R. T. Paine, E. 
K. Pikitch, W. J. Ripple, S. A. Sandin, M. Scheffer, T. W. Schoener, J. B. Shurin, A. R. E. Sinclair, M. E. Soulé, R. Virtanen, and D. A. Wardle. 2011. Trophic downgrading of planet Earth. Science 333:301-306. http://dx.doi.org/10.1126/science.1205106

Fattebert, J., H. S. Robinson, G. Balme, R. Slotow, and L. Hunter. 2015. Structural habitat predicts functional dispersal habitat of a large carnivore: how leopards change spots. Ecological Applications 25(7):1911-1921. http://dx.doi.org/10.1890/14-1631.1

Fitzsimons, J. A., and G. Wescott. 2008. The role of multi-tenure reserve networks in improving reserve design and connectivity. Landscape and Urban Planning 85(3-4):163-173. http://dx.doi. org/10.1016/j.landurbplan.2007.11.001

Gallo, J. A., L. Pasquini, B. Reyers, R. M. Cowling, and C. Town. 2009. The role of private conservation areas in biodiversity representation and target achievement within the Little Karoo region, South Africa. Biological Conservation 142(2):446-454. http://dx.doi.org/10.1016/j.biocon.2008.10.025

Hayward, M. W. 2011. Scarcity in the prey community yields antipredator benefits. Acta Oecologica 37(4):314-320. http://dx.doi. org/10.1016/j.actao.2011.03.003

Hayward, M. W., J. Adendorff, J. O’Brien, A. Sholto-Douglas, C. Bissett, L. C. Moolman, P. Bean, A. Fogarty, D. Howarth, R. Slater, and G. I. H. Kerley. 2007a. Practical considerations for the reintroduction of large, terrestrial, mammalian predators based on reintroductions to South Africa's Eastern Cape Province. The Open Conservation Biology Journal 1:1-11. http://dx.doi. org/10.2174/1874839200701010001

Hayward, M. W., J. O’Brien, and G. I. H. Kerley. 2007b. Carrying capacity of large African predators: predictions and tests. Biological Conservation 139:219-229. http://dx.doi.org/10.1016/j. biocon.2007.06.018

Hilborn, R., J. M. Orensanz, and A. M. Parma. 2005. Institutions, incentives and the future of fisheries. Philosophical Transactions of the Royal Society B: Biological Sciences 360(1453):47-57. http://dx.doi.org/10.1098/rstb.2004.1569

Hunter, L. T. B. 1998. The behavioural ecology of reintroduced lions and cheetahs in the Phinda Resource Reserve, KwaZulu-Natal, South Africa. Dissertation, University of Pretoria, Pretoria, South Africa.

Kerley, G. I. H., and M. Landman. 2006. The impacts of elephants on biodiversity in the Eastern Cape subtropical thickets. South African Journal of Science 102:395-402.

Kettles, R., and R. Slotow. 2009. Management of free-ranging lions on an enclosed game reserve. South African Journal of Wildife Research 39(1):23-33. http://dx.doi.org/10.3957/056.039.0103

Langholz, J. 1996. Economics, objectives, and success of private nature reserves in sub-Saharan Africa and Latin America. Conservation Biology 10(1):271-280. http://dx.doi.org/10.1046/ j.1523-1739.1996.10010271.x

Langholz, J. A., and J. P. Lassoie. 2001. Perils and promise of privately owned protected areas. BioScience 51(12):1079-1085. http://dx.doi.org/10.1641/0006-3568(2001)051[1079:papopo]2.0.co;2

Lindsey, P. A., R. Alexander, M. G. L. Mills, S. Romañach, and R. Woodroffe. 2007. Wildlife viewing preferences of visitors to protected areas in South Africa: implications for the role of ecotourism in conservation. Journal of Ecotourism 6(1):19-33. http://dx.doi.org/10.2167/joe133.0

Lindsey, P., C. J. Tambling, R. Brummer, H. Davies-Mostert, M. Hayward, K. Marnewick, and D. Parker. 2011. Minimum prey and area requirements of the Vulnerable cheetah Acinonyx jubatus: implications for reintroduction and management of the species in South Africa. Oryx 45(04):587-599. http://dx.doi. org/10.1017/s003060531000150x

Maciejewski, K., A. De Vos, G. S. Cumming, C. Moore, and D. Biggs. 2015. Cross-scale feedbacks and scale mismatches as influences on cultural services and the resilience of protected areas. Ecological Applications 25(1):11-23. http://dx.doi. org/10.1890/13-2240.1

Maciejewski, K., and G. I. H. Kerley. 2014a. Understanding tourists' preference for mammal species in private protected areas: Is there a case for extralimital species for ecotourism? PLoS One 9(2):e88192. http://dx.doi.org/10.1371/journal.pone.0088192

Maciejewski, K., and G. I. H. Kerley. 2014b. Elevated elephant density does not improve ecotourism opportunities: convergence in social and ecological objectives. Ecological Applications 24 (5):920-926. http://dx.doi.org/10.1890/13-0935.1

Miller, S. M., C. Bissett, A. Burger, B. Courtenay, T. Dickerson, D. J. Druce, S. Ferreira, P. J. Funston, D. Hofmeyr, P. J. Kilian, W. Matthews, S. Naylor, D. M. Parker, R. Slotow, M. Toft, and D. Zimmermann. 2013. Management of reintroduced lions in small, fenced reserves in South Africa: an assessment and guidelines. South African Journal of Wildlife Research 43(2):138154. http://dx.doi.org/10.3957/056.043.0202

Miller, S. M., and P. J. Funston. 2014. Rapid growth rates of lion (Panthera leo) populations in small, fenced reserves in South Africa: a management dilemma. South African Journal of Wildlife Research 44(1):43-55. http://dx.doi.org/10.3957/056.044.0107

Packer, C., A. Loveridge, S. Canney, T. Caro, S. T. Garnett, M. Pfeifer, K. K. Zander, A. Swanson, D. MacNulty, G. Balme, H. Bauer, C. M. Begg, K. S. Begg, S. Bhalla, C. Bissett, T. Bodasing, H. Brink, A. Burger, A. C. Burton, B. Clegg, S. Dell, A. Delsink, T. Dickerson, S. M. Dloniak, D. Druce, L. Frank, P. Funston, N. Gichohi, R. Groom, C. Hanekom, B. Heath, L. Hunter, H. H. DeIongh, C. J. Joubert, S. M. Kasiki, B. Kissui, W. Knocker, B. Leathem, P. A. Lindsey, S. D. Maclennan, J. W. McNutt, S. M. Miller, S. Naylor, P. Nel, C. Ng'weno, K. Nicholls, J. O. Ogutu, E. Okot-Omoya, B. D. Patterson, A. Plumptre, J. Salerno, K. Skinner, R. Slotow, E. A. Sogbohossou, K. J. Stratford, C. Winterbach, H. Winterbach, and S. Polasky. 2013. Conserving large carnivores: dollars and fence. Ecology Letters 16(5):635641. http://dx.doi.org/10.1111/ele.12091

Pasquini, L., R. M. Cowling, C. Twyman, and J. Wainwright. 2010. Devising appropriate policies and instruments in support of private conservation areas: lessons learned from the Klein Karoo, South Africa. Conservation Biology 24(2):470-478. http:// dx.doi.org/10.1111/j.1523-1739.2009.01344.X

Poiani, K. A., B. D. Richter, M. G. Anderson, and H. E. Richter. 2000. Biodiversity conservation at multiple scales: functional sites, landscapes, and networks. BioScience 50(2):133-146. 
Power, R. J. 2003. Evaluating how many lions a small reserve can sustain. South African Journal of Wildlife Research 33(1):3-11.

R Development Core Team, R. 2013. R: a language and environment for statistical computing. $\mathrm{R}$ Foundation for Statistical Computing, Vienna, Austria.

Selinske, M. J., J. Coetzee, K. Purnell, and A. T. Knight. 2015. Understanding the motivations, satisfaction, and retention of landowners in private land conservation programs. Conservation Letters 8(4):282-289. http://dx.doi.org/10.1111/conl.12154

Skinner, J. D., and C. T. Chimimba. 2005. The mammals of the Southern African subregion. Cambridge University Press, Cambridge. http://dx.doi.org/10.1017/CBO9781107340992

Stolton, S., K. H. Redford, and N. Dudley. 2014. The futures of privately protected areas. Gland, Switzerland.

Tambling, C. J., and J. T. du Toit. 2005. Modelling wildebeest population dynamics: implications of predation and harvesting in a closed system. Journal of Applied Ecology 42:431-441. http:// dx.doi.org/10.1111/j.1365-2664.2005.01039.x 
Appendix 1. The density of free-roaming large predators on 12 private land conservation areas (PLCAs) in the Western and Eastern Cape Provinces of South Africa.

\begin{tabular}{cccc}
\hline & \multicolumn{3}{c}{ Predator density $\left(\# . \mathrm{km}^{-2}\right)$} \\
\cline { 2 - 4 } PLCA & Cheetah & Lion & Spotted hyaena \\
\hline $1^{(\$)}$ & 0.02 & 0.06 & 0 \\
$2^{(\$)}$ & 0.01 & 0.10 & 0 \\
$3^{(\$)}$ & $\mathbf{0 . 0 2}$ & 0.01 & 0 \\
$4^{(\$)}$ & $\mathbf{0 . 0 3}$ & 0.03 & 0 \\
$5^{(\$)}$ & $\mathbf{0 . 0 4}$ & 0.08 & 0 \\
$6^{(\$)}$ & $\mathbf{0 . 1 7}$ & 0 & 0 \\
$7^{(\$)}$ & $\mathbf{0 . 0 5}$ & 0 & 0 \\
$8^{(\$)}$ & $\mathbf{0 . 0 7}$ & 0 & 0 \\
$9^{(\$)}$ & 0 & 0.08 & 0.05 \\
$1^{(\$)}$ & 0 & 0.02 & 0 \\
$11^{(\$)}$ & 0 & 0.01 & 0 \\
$12^{(\$)}$ & present & 0 & 0 \\
\hline
\end{tabular}

NOTE: Bold values indicate densities that were found to be unsustainable (no sustainability estimate was available for spotted hyaena); "present" - predator was present but no count data were available; (\$) - sites for which ecotourism revenue was available. 